\title{
THE VITAL CAPACITY OF CHILDREN
}

\author{
BY \\ H. EVERLEY JONES \\ From the Royal Hospital, Wolverhampton
}

(RECEIVED FOR PUBLICATION JUNE 5, 1955)

In 1846 Hutchinson published an exhaustive treatise on pulmonary function, giving an historical review and describing in detail methods for measuring pulmonary ventilation using, apparently for the first time, a spirometer. Most investigators since then have followed Hutchinson's lead and used spirometers to record their measurements.

The following simple methods of measurement have been those generally used: (1) Vital capacity, which is determined by measuring the maximum amount of air exhaled after a full inspiration; (2) maximum breathing capacity, which is a measurement of the greatest amount of air that can be moved in and out of the chest in a given period of time.

Figures for normal values in adults have been published, but few for children are available. Such figures for American children have been given by Emerson and Green (1921) in a group of boys aged 8 to 15 years and in girls from 7 to 13 years, by Wilson and Edwards (1921) in 85 normal children, 44 boys and 41 girls aged from 6 to 16 years and by Ferris, Whittenberger and Gallagher (1952) in 161 boys aged 5 to 18 years. Robinson (1938) includes recordings for about 20 healthy boys in a detailed study of the relation of physical fitness to age. The only article found dealing with British children is that by Moore and Gibson-Williams (1951), who measured the vital capacity and maximum breathing capacity in 152 healthy boys from 10 to $15 \frac{1}{2}$ years of age.

The recording of such normal values in children presents certain difficulties, notably the impossibility of being certain that a young child is trying his best. For this reason it is necessary to take measurements in a large group of healthy children, to win their confidence by careful explanation of what is required of them and to see that they are not intimidated by the apparatus. Children under 6 years old were found to be too unreliable in their efforts to make their inclusion worthwhile.

In an attempt to provide a set of normal measurements which might be of value, this study was undertaken. Healthy children of both sexes aged 6 to $13 \frac{1}{2}$ years had their vital capacities measured. The maximum breathing capacity was not estimated as the procedure necessary was found to be inaccurate in the younger children, many of whom were unable to maintain the necessary effort for the time required, and it was felt desirable to use a method simple enough to be undertaken in any small hospital physiotherapy department.

\section{Method}

To obtain figures for normal children, patients attending hospital were not used, as many of these suffer from conditions likely to affect pulmonary efficiency and others will have been ill and therefore inactive, with a resulting fall in capacity. To obviate this difficulty, a list of Wolverhampton school children between the ages of 6 and $13 \frac{1}{2}$ years was kindly supplied by Dr. B. Sergeant, senior assistant school medical officer of Wolverhampton. Care was taken to see that the list contained children of all social grades and those chosen were not confined to one school, so that pupils from housing estates on the periphery of the town as well as those from the more crowded centre were included. Letters were sent to the parents of those selected inviting them to attend and stating the purpose for which they were being examined. They were informed that no treatment would be given. More than half of those invited attended, and after discarding a number either on account of some illness or because full cooperation was not obtained, measurements were made on 324 boys and 301 girls. On arrival, a history was taken from the parent, and the child was examined clinically. Those found to be suffering from any (usually respiratory) disease were excluded.

After explaining to the children what was required of of them, heights and weights were recorded while wearing only pants and socks. The chest expansion was then measured and finally the child sat on a stool in front of a Benedict-Roth type of spirometer. Each child was given a clean glass mouth-piece attached to the rubber inlet tube of the instrument and was shown what happened when he blew into the mouth-piece. He was encouraged to inspire as fully as possible and then expire to his maximum ability through the mouth-piece. After a preliminary trial, three such attempts were made and recorded without hurrying the child. It was 
intended to repeat the procedure with the child lying semi-recumbent on a couch, but as it was found in nearly all cases that the figures obtained in the sitting position were greater, the recumbent posture was discarded and a fourth attempt in the sitting position was made. There is no doubt that a number of the subjects might have improved on their results by further practice, as was shown in the boys of Moore and Gibson-Williams (1951), who found a mean increase of $2.8 \%$ in the vital capacities on repeating the tests after an interval of six weeks. This improvement with practice must be remembered when serial determinations are made. In this series, the method described above was adhered to rigidly to try to achieve a constant result in the simplest manner possible, and, in fact, the fourth attempt rarely bettered the third.

Measurements have been recorded in centimetres for height and kilograms for weight and the surface areas have been calculated from the heights and weights using the nomogram in Du Bois' (1936) book.

\section{Results}

Vital capacity is not accurately correlated to age, height and weight as noted by Dreyer (1920), who found a relationship to exist between certain body measurements, weight, chest circumference and stem-length, and published tables (Dreyer, 1919). In adults, West (1920) showed that vital capacity had a much closer relationship to the body surface area than with age, height or weight, although it tends to rise more uniformly with increasing height than with weight (Baldwin, Cournand and Richards, 1948).

As regards children, Wilson and Edwards (1921) found in 44 boys, 6 to 16 years old, an average vital capacity of $1,902 \mathrm{ml}$. for each square metre of body surface and $1,837 \mathrm{ml}$. for 41 girls of the same age for the same area. Emerson and Green (1921) gave

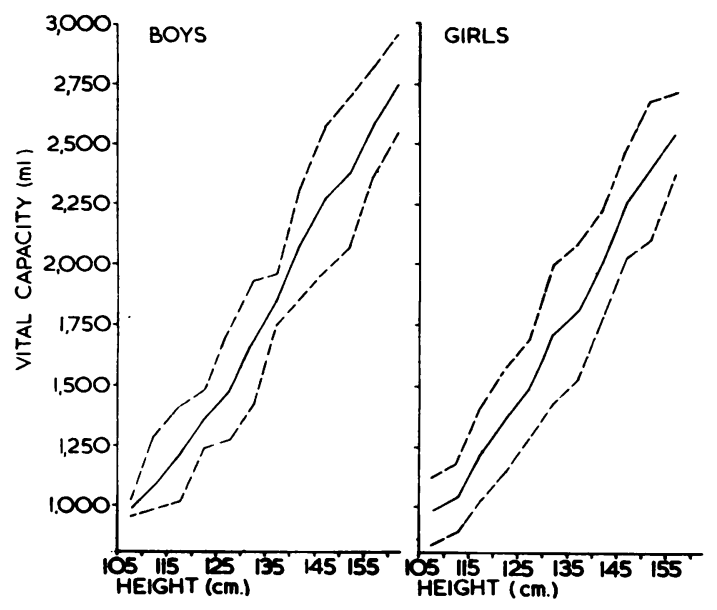

FIG. 1.-Vital capacity-height in boys and girls.

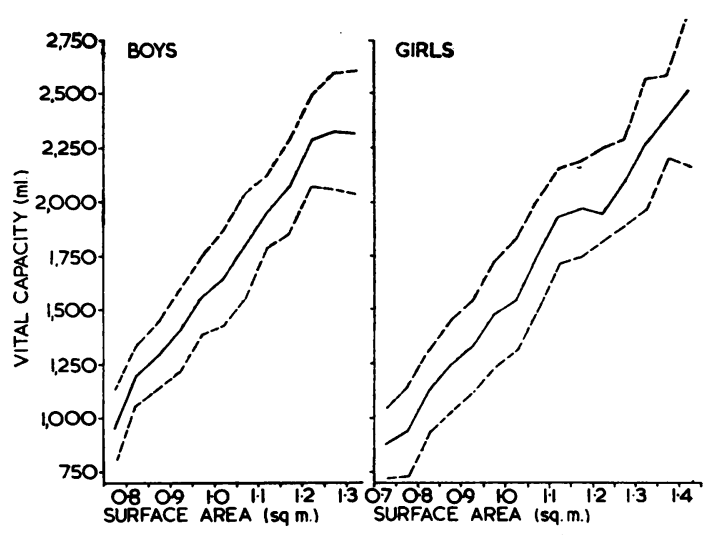

Fig. 2.-Vital capacity-surface area in boys and girls.

rather different figures for boys in four groups based on height, varying from $1,800 \mathrm{ml}$. for a surface area of 1.5 square metres to $800 \mathrm{ml}$. for a surface area of 1 square metre, which is considerably different. Moore and Gibson-Williams (1951) gave figures for 152 boys aged from 10 to $15 \frac{1}{2}$ years and used both vital capacity and maximum breathing capacity in their researches. For vital capacity they conclude that this was best recorded by the formula:

Vital capacity $(\mathrm{ml})=2,.235+90 \cdot 8$ (age13.114)

with $95 \%$ limits approximately $\pm 480 \mathrm{ml}$. for all calculated values.

This last appears to be the only British contribution to the subject as applied to children in recent years. Whitfield, Waterhouse and Arnott (1950) advised the use of four physical attributes: age, height, weight and surface area, for, while any one of these may be effective for an individual who is normal in every respect, this will not be the case

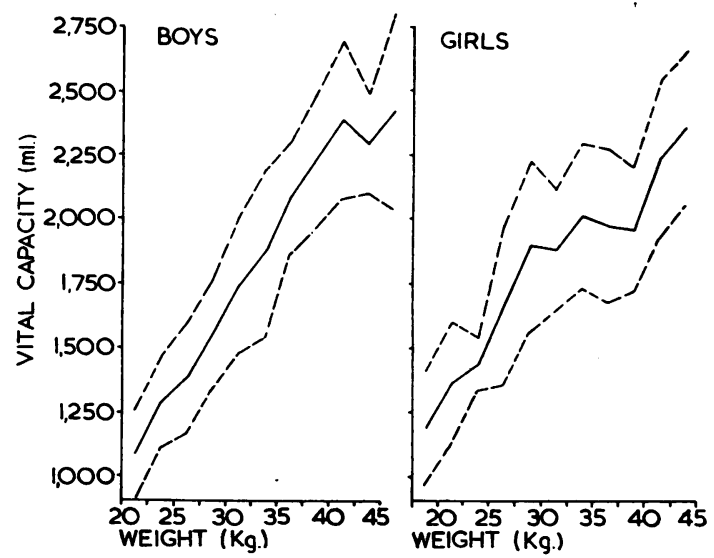

FIG. 3.-Vital capacity-weight in boys and girls. 
VITAL CAPACITY-WEIGHT IN BOYS AND GIRLS

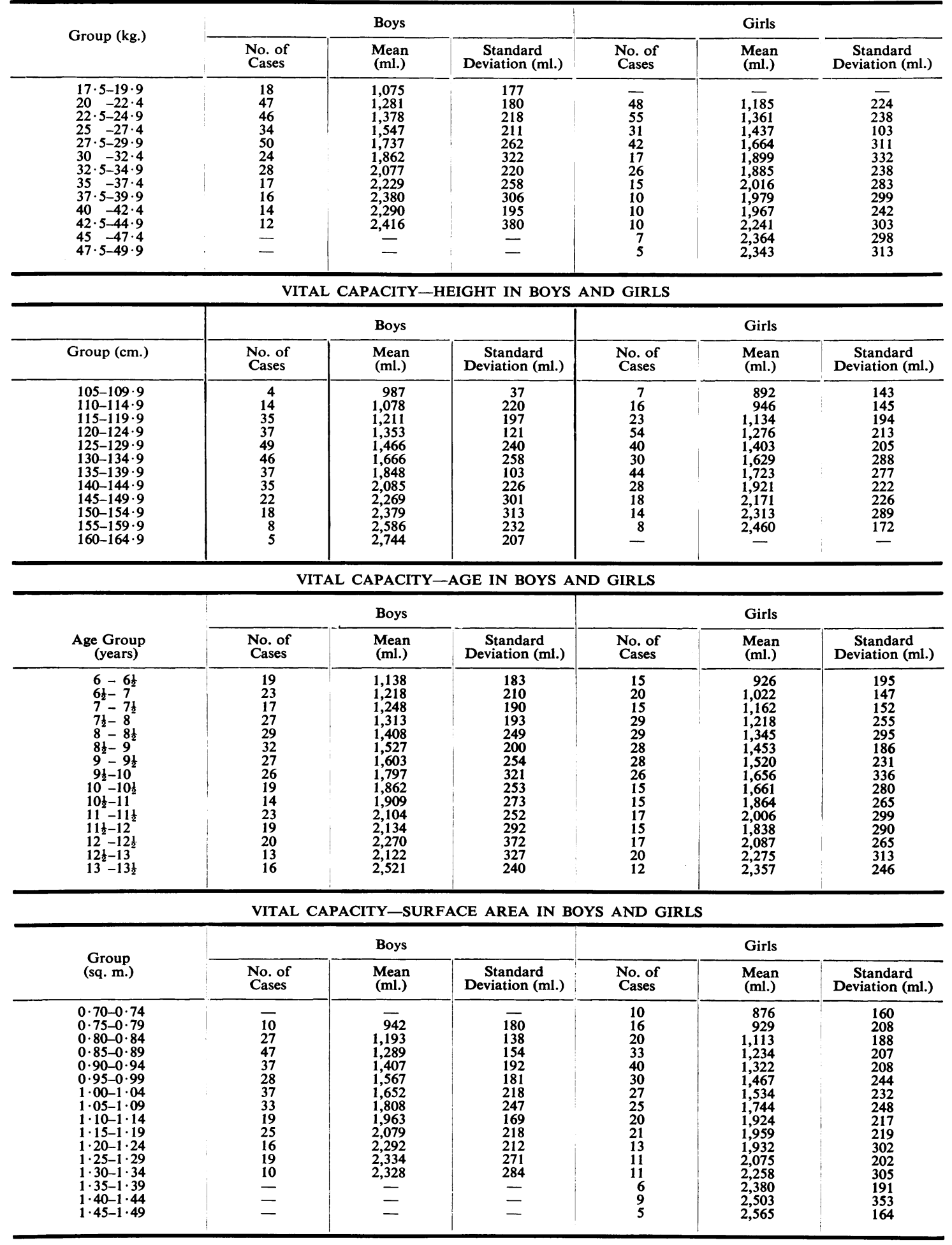




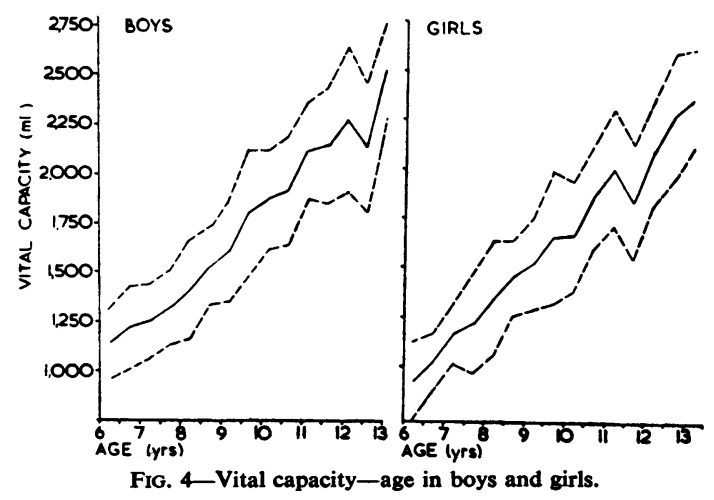

for anyone who is, say, short and fat. In such a person prediction by height is likely to give a reading too low, while one by weight will probably forecast too high a result.

In view of the findings of the workers mentioned above, separate tables have been prepared for age, height, weight and surface area for both sexes. The tables for age are divided into groups of six months, those for height into increments of $5 \mathrm{~cm}$., those for weight into divisions of $2.5 \mathrm{~kg}$., and those for surface area into sections each increasing by 0.05 square metres of body surface. The number of children recorded in the groups for height, weight and surface area tend to be slightly less than the totals for age, as a number, too small to be significant, fell outside the ranges given.

Curves are also given for the mean values (solid lines) and standard deviation ranges, above and below the means (dotted lines). It will be noticed that the most smoothly rising curve in each sex is that recording vital capacity for height, which corroborates the findings of Baldwin et al. (1948). The standard deviations will be seen to be rather large, though on the whole less than the somewhat comparable figures given for boys by Ferris $e t$ al. (1952), probably because the numbers in the groups of the latter are less. The most likely explanation for this is failure of some of the subjects to cooperate fully in the tests. Wilson and Edwards (1921) also noted this and, while agreeing that the human error was chiefly responsible, they felt that some other factor was at work and suggested that perhaps enlargement of the tracheo-bronchial lymph nodes might play a part. This has not been confirmed.
While examining patients who had a past history of pneumonia, a clinical impression was formed that their vital capacities were lower than normal, so to settle this point, a group of 85 children, 42 boys and 43 girls, who had a history of pneumonia in the past, was examined. The vital capacities of these children, who were healthy at the time of examination, were recorded for age, height, weight and surface area, and only if the figures in at least three out of the four readings for each child were below the mean minus the standard deviation were they accepted as abnormal. It was found that in only eight (three boys and five girls) was this the case. In five children (three boys and two girls), the vital capacities were above the mean plus the standard deviation. In those, eight of each sex, who had experienced two or more attacks of pneumonia, two fell into each of the above categories. There appears, therefore, to be no evidence that children who have had pneumonia have lower vital capacities than those who have not.

\section{Summary}

Values for the normal range of vital capacity

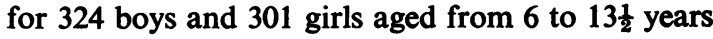
are given.

No evidence has been found that children who have suffered from pneumonia have a lower vital capacity than those who have not.

I should like to express my thanks for the help given by the staff of the School of Physiotherapy at the Royal Hospital, Wolverhampton, in recording these measurements, and to Dr. K. W. Cross, Statistical Officer to the Birmingham Regional Hospital Board, for his statistical assistance.

\section{REFERENCES}

Baldwin, E. de F., Cournand, A. and Richards, D. W. (1948), Medicine, 27, 243.

Dreyer, G. (1919). Lancet, 2, 227

(1920). The Assessment of Physical Fitness. London.

Du Bois, E. F. (1936). Basal Metabolism in Health and Disease, 3 rd ed. Philadelphia.

Emerson, P. W. and Green, H. (1921). Amer. J. Dis. Child., 22, 202.

Ferris, B. G., Whittenberger, J. L. and Gallagher, J. R. (1952). Pediatrics, 9, 659.

Hutchinson, J. (1846). Med.-chir. Trans., 29, 169.

Moore, R. E. and Gibson-Williams, M. G. (1951). Gt Ormond Str. J., 1, no. 2, p. 137.

Robinson, S. (1938). Arbeitsphysiologie, 10, 251.

West, H. F. (1920). Arch. intern. Med., 25, 306.

Whitfield, A. G. W., Waterhouse, J. A. H. and Arnott, W. M. (1950). Brit. J. soc. Med., 4, 113 .

Wilson, M. G. and Edwards, D. J. (1921). Amer. J. Dis. Child., $22,443$. 